\title{
Performance on the Stroop Predicts Treatment Compliance in Cocaine-Dependent Individuals
}

\author{
Chris C Streeter*, I,2,3, Devin B Terhune', Theodore H Whitfield ${ }^{4}$, Staci Gruber ${ }^{2,3}$, Ofra Sarid-Segal ${ }^{1,5}$, \\ Marisa M Silveri' ${ }^{2,3}$, Golfo Tzilos', Maryam Afshar', Elizabeth D Rouse', Hua Tian', Perry F Renshaw',2,3, \\ Domenic A Ciraulo ${ }^{1,3,5}$ and Deborah A Yurgelun-Todd ${ }^{2,3}$
}

'Division of Psychiatry, Boston University School of Medicine, Boston, MA, USA; ${ }^{2}$ Brain Imaging Center, McLean Hospital, Boston, MA, USA; ${ }^{3}$ Department of Psychiatry, Harvard Medical School, Boston, MA, USA; ${ }^{4}$ Biostatistics Solutions Consulting, Boston, MA, USA; ${ }^{5}$ Department of Psychiatry, Boston VA Healthcare System, Boston, MA, USA; ${ }^{6}$ Department of Psychology Wayne State University, Detroit, MI, USA

\begin{abstract}
Treatment dropout is a problem of great prevalence and stands as an obstacle to recovery in cocaine-dependent (CD) individuals. Treatment attrition in CD individuals may result from impairments in cognitive control, which can be reliably measured by the Stroop color-word interference task. The present analyses contrasted baseline performance on the color-naming, word-reading, and interference subtests of the Stroop task in CD subjects who completed a cocaine treatment trial (completers: $N=50$ ) and those who dropped out of the trial before completion (non-completers: $N=24$ ). A logistic regression analysis was used to predict trial completion using three models with the following variables: the Stroop task subscale scores (Stroop model); the Hamilton depression rating scale (HDRS) scores (HDRS model); and both the Stroop task subscale scores and HDRS scores (Stroop and HDRS model). Each model was able to significantly predict group membership (completers vs non-completers) better than a model based on a simple constant (HDRS model $p=0.02$, Stroop model $p=0.006$, and Stroop and HDRS model $p=0.003$ ). Models using the Stroop preformed better than the HDRS model. These findings suggest that the Stroop task can be used to identify cocaine-dependent subjects at risk for treatment dropout. The Stroop task is a widely available, reliable, and valid instrument that can be easily employed to identify and tailor interventions of at risk individuals in the hope of improving treatment compliance.
\end{abstract}

Neuropsychopharmacology (2008) 33, 827-836; doi: I0.I038/sj.npp. I 30 I465; published online I3 June 2007

Keywords: cocaine; prefrontal; Stroop; compliance; neuropsychological testing; executive function

\section{INTRODUCTION}

Dropout from substance abuse treatment in general and cocaine dependence treatment in particular is a serious problem, resulting in reduced treatment efficacy, increased likelihood of relapse, increased medical illness, and social problems related to substance abuse (Alterman et al, 1996; Mulvaney et al, 1999). Conversely, the number of months in treatment for cocaine dependence is associated with decreased cocaine use, improved outcome, and decreased morbidity (Hser et al, 2006). Attrition in cocaine treatment trials is a problem across treatment modalities. Pharmacologic treatment trials for cocaine dependence report dropout rates of $0-84 \%$ (de Lima et al, 2004). Psychotherapy treatment trials for cocaine dependence report dropout rates of 29-41\% (Kang et al, 1991; Simpson et al, 1999).

\footnotetext{
*Correspondence: Dr CC Streeter, Division of Psychiatry, Boston University Medical School, 85 E. Newton St. M9I2E, Boston, MA 02118, USA, Tel: + 1617638 8008, Fax: + 16176388007 ,

E-mail: streeter@bu.edu

Received 6 October 2006; revised 23 March 2007; accepted 26 April 2007
}

Trials that combine pharmacologic treatments with psychotherapy report dropout rates of 30-40\% (Carroll et al, 1994; Elkashef et al, 2005). Variables related to treatment dropout include a number of demographic and socioeconomic factors such as low education, African-American ethnicity, female gender, reporting cocaine as the drug of choice, younger age of subjects, current unemployment, high level of cocaine use during the lead-in period, history of arrests, longer drug use histories, abstinence symptoms, and previous treatment enrollment (Alterman et al, 1996; Siqueland et al, 1998; Mulvaney et al, 1999; King and Canada, 2004; Bisaga et al, 2005).

Cognitive testing has also been used to predict attrition in drug abuse treatment programs (Simpson et al, 1997; Teichner et al, 2002; Aharonovich et al, 2003, 2006). In a cocaine treatment study utilizing cognitive behavioral therapy (CBT) plus a trial of gabapentin or placebo, performance on computerized tests across most cognitive domains was poorer in dropouts relative to completers, independent of pharmacologic status (Aharonovich et al, 2006). This suggests that identification of deficits on cognitive tasks may be a means of identifying subjects at risk for dropout. 
Cognitive control allows the inhibition of a habitual or prepotent response such as drug use and non-compliance with treatment in favor of a more appropriate response such as abstaining from drug use or engaging in treatment. The Stroop Color Word Task is considered to be one of the most reliable and widely used psychometric tests of cognitive control (Stroop, 1935; MacLeod, 1991). For this reason it may be an ideal instrument to screen for individuals at risk for treatment dropout, due to their hypothesized inability to inhibit a prepotent response. The original Stroop task is comprised of three subtests, designed to assess the subject's ability to suppress interfering stimuli. In the color-naming subtest, the subject is asked to report the color of randomly sequenced color rectangles, establishing the tendency to respond to color. In the word-reading subtest, the subject is asked to read color words randomly printed in black ink, establishing a response set to reading color words. In the interference subtest, the subject is given color words, which are printed in an incongruent ink color (eg the word 'red' printed in blue ink). The subject is asked to report the ink color, and therefore has to suppress the tendency to read the color word. There is a strong prepotent tendency to read the presented text of a color word rather than naming the color in which the word is printed.

The Stroop task is believed to test key cognitive processes associated with selective attention, cognitive control, and goal-oriented behavior that supports the ability to select a weaker, task-relevant response in the face of competition from a potentially stronger, task-irrelevant one (Pardo et al, 1990; MacDonald et al, 2000). Difficulty with inhibitory processing is reflected by an increase in time in the interference subtest relative to the color-naming or wordreading subtests. Slowed performance on the interference subtest has been interpreted to reflect difficulty in resisting interference, an inhibitory function associated with frontal cortical integrity (Mesulam, 1985). Subjects with prefrontal impairment have difficulty with this task (Golden, 1976), suggesting that frontally mediated processes are involved in adhering to the goals or rules of the task in the face of a competing, stronger (ie more salient, habitual, or prepotent) response.

The present study assessed whether performance on the Comalli version of the Stroop task (Comalli et al, 1962) was able to predict treatment attrition in cocaine-dependent subjects. It was hypothesized that dropouts would exhibit poorer performance scores on the interference subtest than subjects who completed the course of treatment, suggesting that impairment in the ability to inhibit a prepotent response is a marker for poor treatment compliance.

\section{MATERIALS AND METHODS}

\section{Study Design}

The National Institute on Drug Abuse (NIDA) has developed and implemented a series of treatment trials to evaluate a number of pharmacologic agents as potential treatments for cocaine dependence (Liederman et al, 2000, 2005; Berger et al, 2005; Ciraulo et al, 2005; Elkashef et al, 2005; Winhusen et al, 2005). Boston University School of Medicine was the site of three NIDA-sponsored cocaine dependence treatment trials that were similar in design.
All studies included a CBT platform of weekly individual sessions that were based on a CBT manual developed for cocaine dependence. The trial name, pharmacologic treatments, and length of treatment were as follows: Trial 1, venlafaxine, pramipexole, and placebo, 12 weeks; Trial 2, reserpine and placebo, 12 weeks; and Trial 3, tiagabine and placebo, 17 weeks. As a supplement to the pharmacologic treatment trials, all cocaine-dependent subjects completed imaging studies before randomization and at maximal treatment (weeks 12, 12, and 17). Cocaine-dependent subjects underwent neuropsychological testing concurrent with the first scanning session. The results of the imaging studies have been reported elsewhere ( $\mathrm{Ke}$ et al, 2004; Streeter et al, 2005, 2006). The entrance criteria for the cocaine-dependent subjects were similar in all three studies, allowing comparison across studies. In order to come to the final assessment of the imaging study, subjects had to have completed the clinical trial. Subjects who missed more than two consecutive weeks of treatment were withdrawn from the study, as those on medications would have run out of medication after 2 weeks.

\section{Inclusion/Exclusion Criteria}

All subjects signed informed consent forms that were approved at the appropriate Institutional Review Boards of Boston Medical Center, McLean Hospital, and the Boston VA Healthcare System. Eligible subjects were cocainedependent persons between 18 and 60 years of age enrolled in an NIDA-sponsored treatment study. All cocainedependent subjects met the Diagnostic and Statistical Manual of Mental Disorders - Fourth Edition (DSM-IV) diagnosis of cocaine dependence and reported using cocaine on at least 2-6 occasions within the 28-day period before screening (American Psychiatric Association, 1994). Self-report of current cocaine use was substantiated with 1-3 urine specimens that were positive for the cocaine metabolites over a two-week period before study entry. Women with childbearing capacity were required to use an acceptable method of birth control. Potential subjects were excluded if they had a current dependence on any psychoactive drug other than cocaine, alcohol, or nicotine. In addition, those with neurological or psychiatric disorders requiring immediate treatment or that would have made medication compliance difficult were excluded. Other reasons for exclusion included serious medical illness, current prescription drug treatment, asthma, amenorrhea due to pregnancy, abnormal laboratory results during screening, or contraindication to magnetic resonance scanning. Cocaine-dependent subjects with a current history of alcohol dependence not requiring medical detoxification were accepted.

Due to the high incidence of co-morbidity of cocaine and alcohol dependence in the cocaine-dependent sample population, the following characteristics resulted in exclusion: liver function tests including a gamma-glutamyl transferase greater than three times normal, a history of a complicated alcohol withdrawal such as delirium tremens or seizures, or the need for a medical detoxification. All subject evaluations were reviewed by a psychiatrist with additional qualifications in addictions and many years of experience in 
treating individuals with comorbid alcohol and drug dependence (OS).

\section{Neuropsychological Battery and Other Assessment Instruments}

The neuropsychological test battery was administered by trained psychometricians under the supervision of a neuropsychologist (DYT) at baseline before randomization. Only the results from the Stroop task administered using the Comalli-Kaplan Version that allows for self-correction of errors before moving to the next stimuli are discussed in this paper (Comalli et al, 1962). This version of the Stroop task includes the three subtest conditions previously discussed, which are contained on three stimulus cards sets, each containing 100 stimuli. The order of administration is invariable, and is color naming, followed by word reading, and finally interference. All sections are timed, and both time to complete each condition and errors made are recorded as dependent variables. The results from the larger study analyzing performance on other baseline neuropsychological tasks will be discussed elsewhere.

All subjects were evaluated using the Structured Clinical Interview for DSM-IV Axis I Disorders (SCID): Patient Edition (First et al, 1995) and the Addiction Severity Index (ASI) (McLellan et al, 1992) before randomization. Psychiatric diagnoses were made according to SCID criteria. Measures of alcohol and substance abuse were taken from the ASI, and depression was evaluated using the Hamilton depression rating scale (HDRS) (Hamilton, 1967).

Urine toxicology was obtained three times a week for quantitative analysis of the cocaine metabolite benzoylecgonine (BE). The Preston criteria were used to determine new use (Preston et al, 1997). The Triage ${ }^{\circledR}$ Drugs of Abuse Panel (Biosite ${ }^{\circledR}$ ) was used to test urine samples for the following drugs of abuse: cocaine, tetrahydrocannabanoids, amphetamines, benzodiazepines, and opiates. Average baseline (urine samples collected before the first scan) and total urine (all available urine samples) BE levels were computed by summing the logarithmically transformed urine $\mathrm{BE}$ levels and dividing by the number of available baseline data points or total number of data points, respectively.

\section{Statistical Analyses}

Categorical data were analyzed using $\chi^{2}$-tests and continuous and ordinal data were analyzed using between-groups one-way and factorial ANOVAs. Non-parametric statistics (eg Kruskal-Wallis and Fisher's exact tests) were used when the respective data set violated assumptions of distribution normality or homogeneity of variance. Analyses of covariance (ANCOVA) were used to control for covariates of $a$ priori theoretical interest. Correlational analyses used Pearson's product-moment correlations and the series of direct logistic regression analyses used the 'forced entry' method. Group membership (ie completers and noncompleters) was determined by dichotomizing the predicted log odds of success for the fitted models, assigning subjects to the predicted completer group if the predicted log odds was greater than zero (ie a predicted probability of completion greater than 50\%). Statistical significance required two-tailed $p<0.05$. Analyses employed the commercial statistical analysis systems SAS Version 8.2, STATA 8.2, and SPSS Version 13.0. The primary analyses examined the ability of Stroop task scores to discriminate between completers and non-completers. The secondary analyses explored the effect of urine metabolites for cocaine and other substances of abuse on Stroop task performance.

\section{RESULTS}

\section{Subject Acquisition}

Treatment-seeking cocaine-dependent individuals already enrolled in a treatment study underwent a screening interview at Boston Medical Center, at which time informed consent was obtained for this study. Subjects were considered enrolled in the study when they arrived for the neuropsychological testing at McLean Hospital. Subjects were categorized as completers: subjects who had neuropsychological testing at baseline and returned for the final assessment at McLean Hospital; or non-completers: subjects who had neuropsychological testing at baseline but did not return for the final assessment at McLean Hospital. In Trials 1,2 , and 3 , there were 38,19 , and 17 enrolled subjects who participated in the baseline neuropsychological testing; of these, 7, 6, and 11 did not complete the respective trial, resulting in 50 completers and 24 non-completers. The percentage attendance in the three times a week assessments were $90.2 \pm 10.1 \%$ for the completers and $47.3 \pm 27.5 \%$ for the non-completers $(N=20)$. There were four non-completers that did not attend any assessments after the neuropsychological testing. There were 11 completers from Trial 1 who also participated in Trial 2, three of whom participated in Trial 3, and one completer from Trial 2 who also participated in Trial 3. To avoid testretest artifacts, only the first baseline neuropsychological data were considered for subjects who participated in more than one trial (Table 1).

\section{Demographics}

The completers and non-completers did not differ with respect to any of the measured demographic variables including age, gender distributions, years of education, ethnicity, cocaine use in the preceding 30 days, number of years of cocaine use, and current or past alcohol abuse/ dependence. However, the two groups did exhibit differential patterns of treatment assignment (placebo, medication, and non-randomized), owing to primarily the number of non-randomized subjects in the cohort of non-comple-

Table I Distribution of Completers and Non-Completers (Count and Percentage of Total) by Source Study

\begin{tabular}{lcccc}
\hline & \multicolumn{4}{c}{ Study } \\
\cline { 2 - 5 } & Trial I & Trial 2 & Trial 3 & Total \\
\hline Completed session I & 38 & 19 & 17 & 74 \\
Non-completers (\%) & $7(18)$ & $6(32)$ & $11(65)$ & $24(32)$ \\
Completers (\%) & $31(82)$ & $13(68)$ & $6(35)$ & $50(68)$ \\
\hline
\end{tabular}


Table 2 Demographic Variables (M (SD) (\%)) in Cocaine-Dependent Subjects by Trial Completion (Non-Completers $(N=24)$ and Completers $(N=50))$

\begin{tabular}{|c|c|c|c|c|c|}
\hline & Non-completers & Completers & $\boldsymbol{F}$ & df & $\mathbf{p}$ \\
\hline Age & $41.88(6.19)$ & $45.12(8.19)$ & 2.95 & ।,72 & 0.090 \\
\hline Gender (F/M) & $9 / 15$ & $13 / 37$ & 1.03* & । & 0.31 \\
\hline Education & $12.10(1.81)^{\mathrm{a}}$ & $12.88(2.26)$ & 1.99 & 1,69 & 0.16 \\
\hline Ethnicity & & & $0.30 *$ & 3 & 0.96 \\
\hline African-American (\%) & $20(83)$ & $43(86)$ & & & \\
\hline Multi-racial/other & । (4) & I (2) & & & \\
\hline ASI cocaine use days & $14.85(7.80)^{\mathrm{b}}$ & $16.98(9.44)$ & $0.48^{* * *}$ & । & 0.49 \\
\hline Years of cocaine use & $14.70(6.11)^{b}$ & $15.38(7.78)$ & 0.12 & 1,68 & 0.73 \\
\hline Current alcohol abuse/dependence (\%) & $8 / 20(40)$ & $13 / 50(26)$ & $1.33^{*}$ & । & 0.25 \\
\hline Treatment assignment (placebo/medication) & $9 / 9$ & $21 / 29$ & $0.34 *$ & । & 0.56 \\
\hline
\end{tabular}

*, $\chi^{2} ; * *$, Kruskal-Wallis $\chi^{2} ; * * *$, Fisher's exact test.

${ }^{\mathrm{a}} \mathrm{N}=21$.

${ }^{\mathrm{b}} \mathrm{N}=20$.

${ }^{c} N=18$.

ters. In randomized subjects, the two groups did not exhibit differential treatment assignments (placebo or medication) (Table 2).

\section{Analysis of Stroop Results}

A series of ANOVAs were performed to assess performance differences on the Stroop subtests between completers and non-completers. Completers took significantly less time to finish the color-naming and interference subtests, and also yielded lower derived interference scores (interferencecolor naming). In addition, there was a trend toward completers taking less time on the word-reading subtest relative to non-completers. After a Bonferroni correction for multiple analyses $(\alpha=0.01)$, only color naming and interference remained significantly different between the two groups (Table 3 ).

There were a number of potential covariates that could have affected the Stroop results. For instance, there were trends for the completers to be older and to possess a higher incidence of past alcohol abuse or dependence. In addition, non-completers had significantly higher HDRS scores than completers and a significantly greater percentage of their members received HDRS scores greater than 12, with higher scores indicating greater depressive symptoms (Hamilton, 1967). When age, past alcohol abuse/dependence, and HDRS scores were treated as covariates, there were no changes in the main effects reported above.

\section{Logistic Regression}

A logistic regression analysis was used to predict trial completion. Three models using the following variables
Table 3 Baseline Stroop Subtest Performance Scores in Seconds ( $M$ and $(\mathrm{SD})$ ) in Cocaine-Dependent Subjects as a Function of Trial Completion (Non-Completers $(\mathrm{N}=24)$ and Completers $(N=50))$

\begin{tabular}{lcccccc}
\hline & Non-completers & Completers & $\boldsymbol{F}$ & $\mathbf{d f}$ & $\boldsymbol{p}$ & $\boldsymbol{\eta}_{\mathbf{p}}^{\mathbf{2}}$ \\
\hline Color naming & $77.63(16.19)$ & $66.20(11.94)$ & $8.48^{*}$ & $\mathrm{|}$ & 0.004 & 0.14 \\
Word reading & $61.08(22.24)$ & $51.80(10.08)$ & $2.87 *$ & $\mathrm{1}$ & 0.090 & 0.07 \\
Interference & $163.96(55.80)$ & $132.12(30.43)$ & 10.12 & 1,72 & 0.002 & 0.12 \\
Derived & $86.33(47.7 \mathrm{I})$ & $65.92(26.12)$ & 5.67 & 1,72 & 0.020 & 0.07 \\
interference & & & & & & \\
\hline
\end{tabular}

*, Kruskal-Wallis $\chi^{2}$.

were explored to predict completion: the Stroop task subscale scores (ie color naming, word reading, and interference) (Stroop model); the HDRS scores (HDRS model); and both the Stroop task subscale scores and HDRS scores (Stroop and HDRS model). A fourth model that is pure chance is also reported. Sensitivity (predicted completers/actual completers), specificity (predicted non-completers/actual non-completers), positive predictive value (actual completers/predicted completers), and negative predictive value (actual non-completers/predicted noncompleters) are reported for each model in Table 4.

Each model was able to significantly predict group membership (completers $v s$ non-completers) better than a model based on a simple constant (HDRS model $p=0.02$, $\mathrm{df}=1, \chi^{2}=5.9$; Stroop model $p=0.006, \mathrm{df}=3, \chi^{2}=12.6$; Stroop and HDRS model $p=0.003, \mathrm{df}=4, \chi^{2}=15.9$ ). The HDRS model alone has good sensitivity $(93 \%)$, poor specificity (28\%), the lowest positive predictive value $(75 \%)$, 
Table 4 Logistic Regression Models with 95\% Confidence Intervals

\begin{tabular}{|c|c|c|c|c|}
\hline Model & Sensitivity & Specificity & Positive predictive value & Negative predictive value \\
\hline \multicolumn{5}{|l|}{ Stroop } \\
\hline Point estimates (\%) & 98 & 42 & 78 & 91 \\
\hline $95 \% \mathrm{Cl}$ & $(89,100)$ & $(22,63)$ & $(66,87)$ & $(59,100)$ \\
\hline \multicolumn{5}{|l|}{ HDRS } \\
\hline $95 \% \mathrm{Cl}$ & $(81,99)$ & $(10,53)$ & $(61,86)$ & $(24,91)$ \\
\hline \multicolumn{5}{|l|}{ Stroop and HDRS } \\
\hline Point estimates (\%) & 95 & 50 & 82 & 82 \\
\hline $95 \% \mathrm{Cl}$ & $(84,99)$ & $(26,74)$ & $(68,91)$ & $(48,98)$ \\
\hline
\end{tabular}

Sample size decreases in the models using the HDRS due to a limited number of HDRS data points (ie completers $N=42$ and non-completers $N=18$ ).

and the lowest negative predictive value (62.5\%). The Stroop model has the highest sensitivity (98\%), a fair specificity $(42 \%)$, a good positive predictive value $(78 \%)$, and a very good negative predictive value (91\%); observe that the Stroop model has superior performance in every category compared with the HDRS model. Compared to the Stroop model, the Stroop and HDRS model has a lower sensitivity (95\%), an increased specificity (50\%), and a resulting increased positive predictive value $(82 \%)$ and a decreased negative predictive value $(82 \%)$. The predictive value of all models is better than the pure chance approach.

\section{Concurrent Drug Use and Performance on the Stroop}

This study enrolled treatment-seeking outpatients who were actively using cocaine and other drugs. In order to consider the possible effect(s) of drug use at the time of testing, urine toxicology tests were obtained on the day of testing. There were no differences between the completers and noncompleters in the incidence of positive urine results for cocaine or poly-substance use (poly-substance = cocaine and at least one of the following: THC, amphetamines, benzodiazepines, and opiates) on the day of testing. The majority of subjects tested positive for cocaine use (completers: $74 \%$ and non-completers: $67 \% \quad\left(\chi^{2}=0.53\right.$, $p=0.57))$. THC was the next most common drug present (completers: $24 \%$ and non-completers: 28\%, Fisher's exact $p=0.76$ ), followed by polysubstance use (completers: $24 \%$, non-completers: $22 \%$, Fisher's exact $p=1.00)$. Benzodiazepine, amphetamine, and opiate use were minimal.

\section{Effect of Cocaine Positive Urines on Stroop Results}

Performance on the Stroop subtests was next considered in $2 \times 2$ between-subjects factorial ANOVAs with group (completer and non-completer) and cocaine use (negative and positive), as measured by urine tests on the day of testing, acting as independent variables. The ANOVAs replicated previously found differences between completers and non-completers; specifically, main effects of trial completion upon color naming $(\mathrm{F}(1,67)=7.46, p=0.008)$, interference $(F(1,67)=9.15, p=0.004)$, and derived interference $(\mathrm{F}(1,67)=6.07, p=0.016)$ were found, but no main effect of trial completion was found for word reading $(\mathrm{F}(1,67)=2.32, p=0.13)$. Conversely, no main effects of cocaine use upon any of the performance scores were found, though there was an interaction between trial completion and cocaine use for color naming $(\mathrm{F}(1,67)=4.74, p=0.033)$, with positive use impairing color-naming scores in the non-completers, but not in the completers.

\section{Group Differences in Cocaine Use as Measured by Urine BE Levels}

Urine data were available for 65 subjects, 50 of whom were completers and 15 of whom were non-completers. Baseline urine data were available for 46 of the former group. The relationship between average $\mathrm{BE}$ values (sum of log-transformed quantitative BE values/number of urine samples) and group was explored. Completers $(M=8.36$, $\mathrm{SD}=1.49)$ and non-completers $(\mathrm{M}=8.00, \mathrm{SD}=1.53) \mathrm{did}$ not exhibit differential average baseline urine BE levels $(\mathrm{F}(1,59)=0.67, p=0.42)$.

\section{Urine BE Levels and Neuropsychological Test Performance}

The relationships between urine BE levels and Stroop subtest performance scores were next considered. Average baseline urine BE levels did not significantly correlate with baseline performance scores $(N=61)$ on any of the subtests: color naming $(r=-0.20, p=0.12)$, word reading $(r=-0.11, p=0.40)$, and interference $(r=-0.08$, $p=0.54)$. Average urine $\mathrm{BE}$ levels over the entire trial correlated with baseline performance $(N=65)$ on the color naming $(r=-0.28, p=0.022)$, but not the word reading 
$(r=-0.11, p=0.41)$ or interference $(r=-0.12, p=0.36)$ subtests. When a Bonferroni correction for multiple analyses was performed, the $\alpha$-level decreased to 0.008 , rendering all of the correlations nonsignificant.

Another series of ANCOVAs on Stroop subtests included baseline poly-substance Triage $^{\circledR}$ results as a covariate and trial completion (completers $(N=45)$ and noncompleters $(N=18))$ as the independent variable. Main effects of trial completion remained significant for color naming $\left(\mathrm{F}(1,60)=9.22, p=0.004, \eta_{\mathrm{p}}^{2}=0.13\right)$, word reading $\left(\mathrm{F}(1,60)=5.52, p=0.022, \eta_{\mathrm{p}}^{2}=0.08\right)$, interference $(\mathrm{F}(1,60)=$ $\left.8.52, p=0.005, \eta_{\mathrm{p}}^{2}=0.12\right)$, and derived interference $(\mathrm{F}(1,60)=$ 4.07, $\left.p=0.048, \eta_{\mathrm{p}}^{2}=0.06\right)$. Baseline poly-substance use did not exhibit an independent effect in any of the analyses.

\section{DISCUSSION}

There was a significant difference between the completers and non-completers on the performance scores of color naming and interference after a Bonferroni correction for multiple analyses. The decreased performance on the interference subtest by the non-completers is consistent with the primary hypothesis that poor performance on the Stroop interference subtest would predict treatment dropout.

Three predictive models based on logistic regression were considered in the study: the Stroop model using only Stroop task subscale scores (ie color naming, word reading, and interference); the HDRS model using only the HDRS scores; and the Stroop and HDRS model using both the Stroop task subscale scores and HDRS scores. These models were evaluated by considering sensitivity, specificity, positive predictive values, and negative predictive values. The HDRS model was dominated in all categories by the Stroop model and the Stroop and HDRS model. Therefore the focus of the discussion will be on the models that employ the Stroop task subscales. The Stroop and HDRS model has a superior specificity and positive predictive value compared with the Stroop model. However, the Stroop model had superior sensitivity and negative predictive value. The choice of which model to use would depend on the relative importance of identifying completers $v s$ non-completers. If the primary concern is the correct identification of noncompleters such that additional resources could be employed to improve retention in treatment, then the Stroop model would be the preferred model. It should be noted that subjects in this study were at most mildly depressed based on HDRS scores and the importance of the HDRS in more severely depressed subjects cannot be commented on. The improvement in prediction ability of the model after the addition of the HDRS scores suggests that affective state contributes to treatment compliance. This is not surprising as decreased activity in the cingulate cortex and other prefrontal regions has been reported in both depressed individuals and cocaine-dependent individuals with impaired performance on the Stroop (Mayberg, 1997; Bolla et al, 2004). Most reports of neuropsychological testing in cocaine-dependent subjects have been completed when subjects are in varying degrees of abstinence (Manschreck et al, 1990; O’Malley et al, 1992; Mittenberg and Motta,
1993; Beatty et al, 1995; Bolla et al, 1998, 1999, 2000). The current study differed from previous studies in that subjects were outpatients and still actively using cocaine and other drugs. Notably, there were no differences between completers and non-completers for the presence of cocaine or other tested substances of abuses in urine samples obtained on the day of testing. The presence of cocaine alone or polysubstance use on the day of testing was not associated with performance scores on the three Stroop subtests, nor was there a trial completion $\times$ cocaine use interaction.

In addition to urine toxicology results on the day of testing, a quantitative assessment of cocaine use during the baseline and treatment period was made using logtransformed quantitative urine BE levels. There was no significant difference in baseline quantitative assessments between the groups and no correlations were found between baseline quantitative $\mathrm{BE}$ values and performance on the Stroop subtests. Combined baseline and treatment quantitative cocaine urine $\mathrm{BE}$ levels correlated with color naming but not word reading or interference, though the former finding was not significant after correcting for multiple analyses. Prior studies have reported a relation between the amount of cocaine use as determined by self-report and performance on neuropsychological tests in abstinent cocaine-dependent subjects (Bolla et al, 1999). The differences in the use of self-report $v s$ urine analysis as a measure of cocaine use and abstinent $v s$ actively using cocainedependent subjects may explain the differences in the results.

One notable strength of this study is the inclusion of carefully screened, well-matched groups. A strength and weakness of the study is the ongoing use of cocaine and other substances of abuse. While the degree of substance use was not controlled for, there was no difference between groups for the percentage of positive urines for cocaine metabolites or other substances of abuse on the day of testing, nor was there a difference between quantitative urine $\mathrm{BE}$ values. The presence of ongoing cocaine use increases the generalizability of these findings to actively using cocaine-dependent subjects.

There is mounting evidence that the prefrontal cortex (PFC) and associated circuits are affected by cocaine dependence (Goldstein and Volkow, 2002). Anatomic studies of cocaine-dependent individuals have identified the following changes in the PFC: reduced gray matter (Franklin et al, 2002; Matochik et al, 2003), decreased white matter integrity ( $\operatorname{Lim}$ et $a l, 2002$ ), and increased white matter hyperintensities (Lyoo et al, 2004). Physiologic studies have shown decreased metabolism in the orbitofrontal cortex (Volkow et al, 1988) and increased cerebrovascular resistance in the arteries that supply the PFC (Herning et al, 1999). Some reports of neuropsychological testing in cocaine using subjects have identified decreased performance on tests that require the support of prefrontal structures (Ardila et al, 1991; Berry et al, 1993; Beatty et al, 1995; van Gorp et al, 1999; Di Sclafani et al, 2002). A relationship between the amount of cocaine consumed and neuropsychological deficits in attention, planning, mental flexibility, executive function, and psychomotor function have been reported (Bolla et al, 1998, 1999, 2000). In a meta-analysis of 15 neuropsychological studies comparing cocaine-dependent subjects to normal controls, the majority 
of studies indicated some deficits in attention, learning and memory, response speed, and some tasks of executive functions (Jovanovski et al, 2005). In this meta-analysis, cocaine-using subjects demonstrated decreased performance on the Stroop, suggesting impairment on this task is a common finding in this population.

A prepotent response is a habitual response that may not be appropriate for the current circumstance. An example would be driving on the right side of the road. This is an appropriate and prepotent response for drivers in the United States. However, when a United States driver goes to the United Kingdom, it is no longer appropriate to drive on the right side of the road, although it is still the prepotent response. Cognitive control is needed to consistently select driving on the left side of the road. However after an extended period of driving in the United Kingdom, the prepotent response through repetition can be changed from driving on the right side of the road to driving on the left side of the road. Using the same analogy for the behavior of cocaine-dependent individuals, the prepotent response in cocaine-dependent individuals is treatment non-compliance and cocaine use; however, the goal is to change the prepotent response to treatment compliance and abstinence.

Evidence that drug-related stimuli decrease the brain's ability to inhibit a prepotent response is provided by studies utilizing a modification of the original Stroop task, the emotional Stroop task. In this modification, the color words are replaced with words that are germane to the respective substance of abuse (eg beer for alcoholics and crack for cocaine-dependent individuals) (Cox et al, 1999; Hester et al, 2006). Longer interference scores for emotion-laden words are interpreted as a preoccupation with the drugrelated stimuli. Increased interference time for drug-related words has been shown in subjects with dependence on cocaine (Copersino et al, 2004; Carpenter et al, 2006; Hester et al, 2006), alcohol (Bauer and Cox, 1998; Cox et al, 2002; Lusher et al, 2004), heroin (Franken et al, 2000), and nicotine (Gross et al, 1993; Wertz and Sayette, 2001; Waters et al, 2003). It has been proposed that this preoccupation with drug-related stimuli is a form of attentional bias thought to underlie relapse (Franken, 2003; Copersino et al, 2004).

A number of functional imaging studies using the Stroop in normal subjects have shown increased activation of the anterior cingulate cortex (ACC) (Pardo et al, 1990; Carter et al, 1995; Peterson et al, 1999; Gruber et al, 2002). An fMRI study of cocaine abusers, using a modified version of the Goldman Stroop task, demonstrated less activation of the left ACC and right lateral PFC and increased activation of the right ACC compared to controls (Bolla et al, 2004). Subjects with the highest cocaine use before the study showed the lowest activation of prefrontal structures suggesting that cocaine use compromises the activation of the prefrontal regions involved in executive function (Bolla et al, 2004). Using a GO-NO-GO paradigm that also requires the inhibition of a prepotent response, cocaine-using subjects exhibited greater errors of omission and commission and decreased activation of the ACC and right PFC compared to controls (Kaufman et al, 2003). Tasks of cognitive control involve at least two areas of the PFC, the dorsolateral prefrontal cortex (DLPFC), and the ACC
(MacDonald et al, 2000). The DLPFC is involved in representing and maintaining the attentional demands of the task in working memory, whereas the ACC monitors the competition between processes that conflict during task performance, such as when a task elicits a prepotent but inappropriate response (Carter et al, 1998; Kiehl et al, 2000; Barch et al, 2001).

Two cognitive functions that are relevant to this discussion are selective attention and cognitive control. Selective attention can be voluntary (active, directed, topdown, controlled) or involuntary (reactive, passive, bottomup, automatic), with voluntary controlled attention being inversely proportional to automatic attention (Franken, 2003). Selective attention supports the behavior of processing relevant stimuli, while cognitive control, another top-down function, allows an individual to select the appropriate response, even when it is not the prepotent response (Carter et al, 1998; Kiehl et al, 2000; Barch et al, 2001). Cognitive control, as measured by the Stroop, is hypothesized to be a parallel-distributed system, which also has inherently limited capacity (Cohen et al, 1990). However, repeated selection of the weaker response can strengthen the pathway to that response, effectively shifting a weaker response to a prepotent response (Miller and Cohen, 2001).

In cocaine-dependent subjects, decreased performance on the Stroop and other tasks of cognitive control may be due to two related and additive factors. As cited above, there is substantial evidence that in cocaine-dependent individuals, prefrontal structures and functions dependent on prefrontal regions are different compared to controls. In addition to these anatomically localized dysfunctions, cocaine-dependent individuals respond to environmental stimuli in the form of drug-salient stimuli with attentional bias, a type of involuntary attention and ruminative craving, a form of working memory (Bonson et al, 2002). Increases in working memory demands are related to decreased performance on tests of cognitive control (Hester and Garavan, 2004). Continuing with the position that selective attention and cognitive capacity are both limited capacity systems (Miller and Cohen, 2001; Franken, 2003), drug-salient stimuli would decrease the capacity of these systems to perform in a top-down manner. It is worth noting that top-down/ voluntary modes of performance in these limited capacity systems require the support of the DLPFC and ACC, the same regions that are activated by bottom-up/involuntary modes of performance during cocaine-related cue-induced craving in cocaine-dependent subjects as shown by fMRI and positron emission tomography studies (Grant et al, 1996; Maas et al, 1998; Childress et al, 1999).

In cocaine-dependent subjects, Stroop studies using either cocaine-related stimuli or incongruent-color word stimuli have both shown impairment (Hester et al, 2006). This suggests that the incongruent-color word stimuli version of the Stroop can be used to detect impaired performance in cocaine-dependent individuals for the purposes of identifying individuals at risk for treatment dropout. While both paradigms provide valuable information, the color word version of the Stroop task is widely available and can easily be incorporated into a treatment protocol, thus allowing individuals with decreased performance on such tasks to be identified (MacLeod, 1991). 
As stated above, by repeatedly choosing a response, that response can be strengthened to become a prepotent response (Miller and Cohen, 2001). The Stroop task is a measure of an individual's ability to inhibit a prepotent response. It would be expected that cocaine-dependent subjects with poor performance on the Stroop with the associated impairment in response inhibition would be at increased risk for dropout early in treatment when the prepotent responses of cocaine use and treatment noncompliance have not yet been adequately addressed. Identification of and subsequent tailoring of interventions to address neurocognitive deficits and comorbid mood disorders, when applied at the early stages of treatment, may enhance compliance and thus retention among vulnerable individuals. With improved treatment retention comes further opportunities for implementing interventions targeted at shifting the prepotent response from drug use and treatment noncompliance to that of abstinence and treatment compliance.

\section{ACKNOWLEDGEMENTS}

This study was supported, in part, by grants from the National Institute of Drug Abuse (DA09448 and DA15116 to PFR, DA50038 to DAC), the National Institute on Alcohol Abuse and Alcoholism (K23AA13149 to CCS), VA Career Development Award to CCS, and Gennaro Acampora Charity Trust to the Division of Psychiatry, Boston Medical Center.

\section{DISCLOSURE/CONFLICT OF INTEREST}

The author(s) declare that, except for income received from their primary employer, no financial support or compensation has been received from any individual or corporate entity over the past 3 years for research or professional service except as listed below excluding National Institute of Health funding and there are no personal financial holdings that could be perceived as constituting a potential conflict of interest.

CC Streeter: Risk Management Foundation of the Harvard Medical Institutions, Inc., Karns Law Group, Norcal Mutual Insurance Company, Deluca and Weizenbaum LTD, Pegalis and Ericson, LLC, UCB Pharma, Bristol Myers Squibb; TH Whitfield: AstraZenica; O Sarid-Segal: American Psychiatric Association/Reckitt Benckiser, UCB Pharma, Bristol Myers Squibb, Sanofi Aventis, Ortho McNeil Pharmacutical, Alkermers, Lippincott Williams and Wilkins, Humana Press; M Afshar: UCB Pharma, Bristol Myers Squibb, Sanofi Aventis, Ortho McNeil Pharmacutical, Alkermers; PF Renshaw: GlaxoSmithKline, Novartis, Kyowa Hakko; DA Ciraulo: Alkermes, American Psychiatric Press, Inc., Astra Zeneca, Bristol Myers Squibb, Catalyst Pharmaceutical Partners, Center for Substance Abuse Treatment (CSAT), Cephalon, Complete Healthcare Communication (OrthoMcNeil 2007), Discovery International, DuPont Pharmaceuticals, Food and Drug Administration, Harvard University, Health Learning Systems, A Division of CommonHealth LP (Ortho-McNeil 2004), Humana Press, Johnson \& Johnson, Lipha Pharmaceuticals, Lippincott Williams \& Wilkins, Ortho-McNeil, UCB Pharma; DA Yurgelun-Todd: Eli Lilly,
Inc., Janssen Medical Affairs, Kyowa Hakko, Novartis Pharmaceuticals Corporation.

\section{REFERENCES}

Aharonovich E, Hasin DS, Brooks AC, Liu X, Bisaga A, Nunes EV (2006). Cognitive deficits predict low treatment retention in cocaine dependent patients. Drug Alcohol Depend 81: 313-322.

Aharonovich E, Nunes E, Hasin D (2003). Cognitive impairment, retention and abstinence among cocaine abusers in cognitivebehavioral treatment. Drug Alcohol Depend 71: 207-211.

Alterman AI, McKay JR, Mulvaney FD, McLellan AT (1996). Prediction of attrition from day hospital treatment in lower socioeconomic cocaine-dependent men. Drug Alcohol Depend 40: 227-233.

American Psychiatric Association (1994). Diagnostic and Statistical Manual of Mental Disorders, 4th edn. American Psychiatric Association: Washington, DC.

Ardila A, Rosselli M, Strumwasser S (1991). Neuropsychological deficits in chronic cocaine abusers. Int J Neurosci 57: 73-79.

Barch DM, Braver TS, Akbudak E, Conturo T, Ollinger J, Snyder A (2001). Anterior cingulate cortex and response conflict: effects of response modality and processing domain. Cereb Cortex 11: 837-848.

Bauer D, Cox WM (1998). Alcohol-related words are distracting to both alcohol abusers and non-abusers in the Stroop colournaming task. Addiction 93: 1539-1542.

Beatty WW, Katzung VM, Moreland VJ, Nixon SJ (1995). Neuropsychological performance of recently abstinent alcoholics and cocaine abusers. Drug Alcohol Depend 37: 247-253.

Berger SP, Winhusen TM, Somoza EC, Harrer JM, Mezinskis JP, Leiderman DB et al (2005). A medication screening trial evaluation of reserpine, gabapentin and lamotrigine pharmacotherapy of cocaine dependence. Addiction 100(Suppl 1): 58-67.

Berry J, van Gorp WG, Herzberg DS, Hinkin C, Boone K, Steinman $\mathrm{L}$ et al (1993). Neuropsychological deficits in abstinent cocaine abusers: preliminary findings after two weeks of abstinence. Drug Alcohol Depend 32: 231-237.

Bisaga A, Aharonovich E, Garawi F, Levin FR, Rubin E, Raby WN et al (2005). Utility of lead-in period in cocaine dependence pharmacotherapy trials. Drug Alcohol Depend 77: 7-11.

Bolla K, Ernst M, Kiehl K, Mouratidis M, Eldreth D, Contoreggi C et al (2004). Prefrontal cortical dysfunction in abstinent cocaine abusers. J Neuropsychiatry Clin Neurosci 16: 456-464.

Bolla K, Rothman R, Cadet J (1999). Dose-related neurobehavioral effects of chronic cocaine use. J Neuropsychiatry Clin Neurosci 11: 361-369.

Bolla KI, Cadet JL, London ED (1998). The neuropsychiatry of chronic cocaine abuse. J Neuropsychiatry Clin Neurosci 10: 280-289.

Bolla KI, Funderburk FR, Cadet JL (2000). Differential effects of cocaine and cocaine alcohol on neurocognitive performance. Neurology 54: 2285-2292.

Bonson KR, Grant SJ, Contoreggi CS, Links JM, Metcalfe J, Weyl HL et al (2002). Neural systems and cue-induced cocaine craving. Neuropsychopharmacology 26: 376-386.

Carpenter K, Schreiber E, Church S, McDowell D (2006). Drug Stroop performance: relationships with primary substance of use and treatment outcome in a drug-dependent outpatient sample. Addict Behav 31: 174-181.

Carroll KM, Rounsaville BJ, Gordon LT, Nich C, Jatlow P, Bisighini RM et al (1994). Psychotherapy and pharmacotherapy for ambulatory cocaine abusers. Arch Gen Psychiatry 51: 177-187.

Carter CS, Braver TS, Barch DM, Botvinick MM, Noll D, Cohen JD (1998). Anterior cingulate cortex, error detection, and the online monitoring of performance. Science 280: 747-749. 
Carter CS, Mintun M, Cohen JD (1995). Interference and facilitation effects during selective attention: an H215O PET study of Stroop task performance. Neuroimage 2: 264-272.

Childress AR, Mozley PD, McElgin W, Fitzgerald J, Reivich M, O’Brien CP (1999). Limbic activation during cue-induced cocaine craving. Am J Psychiatry 156: 11-18.

Ciraulo D, Sarid-Segal O, Knapp C, Ciraulo A, LoCastro J, Bloch D et al (2005). Efficacy screening trials of paroxetine, pentoxifylline, riluzole, pramipexole, and venlafaxine in cocaine dependence. Addiction 100(Suppl 1): 12-22.

Cohen JD, Dunbar K, McClelland JL (1990). On the control of automatic processes: a parallel distributed processing account of the Stroop effect. Psychol Review 97: 332-361.

Comalli Jr P, Wapner S, Werner H (1962). Interference effects of Stroop color-word test in childhood, adulthood, and aging. J Genet Psychol 100: 47-53.

Copersino ML, Serper MR, Vadhan N, Goldberg BR, Richarme D, Chou JC et al (2004). Cocaine craving and attentional bias in cocaine-dependent schizophrenic patients. Psychiatry Res 128: 209-218.

Cox W, Hogan L, Kristian M, Race J (2002). Alcohol attentional bias as a predictor of alcohol abusers' treatment outcome. Drug Alcohol Depend 68: 237-243.

Cox WM, Yeates GN, Regan CM (1999). Effects of alcohol cues on cognitive processing in heavy and light drinkers. Drug Alcohol Depend 55: 85-89.

de Lima MS, de Oliveira Soares BG, Reisser AA, Farrell M (2004). Pharmacological treatment of cocaine dependence: a systematic review. Addiction 97: 931-949.

Di Sclafani V, Tolou-Shams M, Price LJ, Fein G (2002). Neuropsychological performance of individuals dependent on crack-cocaine, or crack-cocaine and alcohol, at 6 weeks and 6 months of abstinence. Drug Alcohol Depend 66: 161-171.

Elkashef A, Holmes TH, Bloch DA, Shoptaw S, Kampman K, Reid MS et al (2005). Retrospective analyses of pooled data from CREST I and CREST II trials for treatment of cocaine dependence. Addiction 100(Suppl 1): 91-101.

First MB, Spitzer R, Gibbon M, Williams J (1995). Structured Clinical Interview for DSM-IV Axis I Disorders: Patient Edition (SCID-I/P, Version 2.0). Biometric Research Dept, New York State University: New York.

Franken IHA (2003). Drug craving and addiction: integrating psychological and neuropsychological approaches. Prog Neuropsychopharmacol Biol Psychiatry 27: 563-579.

Franken IHA, Kroon LY, Weirs RW, Jansen A (2000). Selective cognitive processing of drug cues in heroin dependence. $J$ Psychopharmacol 14: 395-400.

Franklin T, Acton P, Maldjian J, Gray J, Croft J, Dackis C et al (2002). Decreased gray matter concentration in the insular, orbitofrontal, cingulate and temporal cortices of cocaine patients. Biol Psychiatry 51: 134-142.

Golden CJ (1976). Identification of brain disorders by the Stroop Color and Word Test. J Clin Psychol 32: 654-658.

Goldstein RZ, Volkow ND (2002). Drug addiction and its underlying neurobiological basis: neuroimaging evidence for the involvement of the frontal cortex. Am J Psychiatry 159: $1642-1652$.

Grant S, London ED, Newlin DB, Villemagne VL, Liu X, Contoreggi $C$ et al (1996). Activation of memory circuits during cue-elicited cocaine craving. Proc Natl Acad Sci USA 93: 12040-12045.

Gross TM, Jarvik ME, Rosenblatt MR (1993). Nicotine abstinence produces content-specific Stroop interference. Psychopharmacology (Berlin) 110: 333-336.

Gruber SA, Rogowska J, Holcomb P, Soraci S, Yurgelun-Todd D (2002). Stroop performance in normal control subjects: an fMRI study. Neuroimage 16: 349-360.

Hamilton M (1967). Development of a rating scale for primary depressive illness. Br J Soc Clin Psychol 6: 278-296.
Herning RI, King DE, Better WE, Cadet JL (1999). Neurovascular deficits in cocaine abusers. Neuropsychopharmacology 21: $110-118$.

Hester R, Dixon V, Garavan H (2006). A consistent attentional bias for drug-related material in active cocaine users across word and picture versions of the emotional Stroop task. Drug Alcohol Depend 81: 251-257.

Hester R, Garavan H (2004). Executive dysfunction in cocaine addiction: evidence for discordant frontal, cingulate, and cerebellar activity. J Neurosci 24: 11017-11022.

Hser Y, Stark ME, Paredes A, Huang D, Anglin MD, Rawson R (2006). A 12-year follow-up of a treated cocaine-dependent sample. J Subst Abuse Treat 30: 219-226.

Jovanovski D, Erb S, Zakzanis KK (2005). Neurocognitive deficits in cocaine users: a quantitative review of the evidence. J Clin Exp Neuropsychol 27: 189-204.

Kang SY, Kleinman PH, Woody GE, Millman RB, Todd TC, Kemp J et al (1991). Outcomes of cocaine abusers after once-a-week psychotherapy. Am J Psychiatry 148: 630-635.

Kaufman J, Ross T, Stein E, Garavan H (2003). Cingulate hypoactivity in cocaine users during a GO-NOGO task as revealed by event-related functional magnetic resonance imaging. J Neurosci 23: 7839-7843.

Ke Y, Streeter CC, Nassar LE, Sarid-Segal O, Hennen J, YurgelunTodd DA et al (2004). Frontal lobe GABA levels in cocaine dependence: a two-dimensional, J-resolved magnetic resonance spectroscopy study. Psychiatry Res 130: 283-293.

Kiehl KA, Liddle PF, Hopfinger JB (2000). Error processing and the rostral anterior cingulate: an event-related fMRI study. Psychophysiology 37: 216-223.

King AC, Canada SA (2004). Client-related predictors of early treatment drop-out in a substance abuse clinic exclusively employing individual therapy. J Subst Abuse Treat 26: 189-195.

Leiderman DB, Shoptaw S, Montgomery A, Bloch DA, Elkashef A, LoCastro J et al (2005). Cocaine Rapid Efficacy Screening Trial (CREST): a paradigm for the controlled evaluation of candidate medications for cocaine dependence. Addiction 100(Suppl 1): $1-11$.

Liederman D, Winhusin T, Somoza E, Montgomery A, Berger P (2000). A modified placebo controlled study for the treatment of cocaine dependence using reserpine, gabapentin, or lamotrigine versus an unmatched placebo (CREST-I). Study Report, NIDA.

Lim KO, Choi SJ, Pomara N, Wolkin A, Rotrosen JP (2002). Reduced frontal white matter integrity in cocaine dependence: a controlled diffusion tensor imaging study. Biol Psychiatry 51: 890-895.

Lusher J, Chandler C, Ball D (2004). Alcohol dependence and the alcohol Stroop paradigm: evidence and issues. Drug Alcohol Depend 75: 225-231.

Lyoo IK, Streeter CC, Ahn KH, Lee HK, Pollack MH, Silveri MM et al (2004). White matter hyperintensities in subjects with cocaine and opiate-dependence and healthy comparison subjects. Psychiatry Res 131: 135-145.

Maas LC, Lukas SE, Kaufman MJ, Weiss RD, Daniels SL, Rogers VW et al (1998). Functional magnetic resonance imaging of human brain activation during cue-induced cocaine craving. $\mathrm{Am}$ I Psychiatry 155: 124-126.

MacDonald III AW, Cohen JD, Stenger VA, Carter CS (2000). Dissociating the role of the dorsolateral prefrontal and anterior cingulate cortex in cognitive control. Science 288: 1835-1838.

MacLeod C (1991). Half a century of research on the Stroop effect: an integrative review. Psychol Bull 109: 163-203.

Manschreck TC, Schneyer ML, Weisstein CC, Laughery J, Rosenthal J, Celada T et al (1990). Freebase cocaine and memory. Compr Psychiatry 31: 369-375.

Matochik JA, London ED, Eldreth DA, Cadet JL, Bolla KI (2003). Frontal cortical tissue composition in abstinent cocaine abusers: a magnetic resonance imaging study. Neuroimage 19: 1095-1102. 
Mayberg H (1997). Limbic-cortical dysregulation. In: Salloway S, Malloy P, Cummings J (eds). The Neuropsychiatry of Limbic and Subcortical Disorders. American Psychiatric Press: Washington, DC. pp 167-178.

McLellan A, Kushner H, Metzger D, Peters R, Smith I, Grissom G et al (1992). The fifth edition of the Addiction Severity Index. J Subst Abuse Treat 9: 119-213.

Mesulam MM (1985). Principles of Behavioral Neurology. FA Davis Co.: Philadelphia.

Miller EK, Cohen JD (2001). An integrative theory of prefrontal cortex function. Annu Rev Neurosci 24: 167-202.

Mittenberg W, Motta S (1993). Effects of chronic cocaine abuse on memory and learning. Arch Clin Neuropsychol 8: 477-483.

Mulvaney FD, Alterman AI, Boardman CR, Kampman K (1999). Cocaine abstinence symptomatology and treatment attrition. J Subst Abuse Treat 16: 129-135.

O'Malley S, Adamse M, Heaton RK, Gawin FH (1992). Neuropsychological impairment in chronic cocaine abusers. Am J Drug Alcohol Abuse 18: 131-144.

Pardo JV, Pardo PJ, Janer KW, Raichle ME (1990). The anterior cingulate cortex mediates processing selection in the Stroop attentional conflict paradigm. Proc Natl Acad Sci USA 87: 256-259.

Peterson BS, Skudlarski P, Gatenby JC, Zhang H, Anderson AW, Gore JC (1999). An fMRI study of Stroop word-color interference: evidence for cingulate subregions subserving multiple distributed attentional systems. Biol Psychiatry 45: 1237-1258.

Preston KL, Silverman K, Schuster CR, Cone EJ (1997). Assessment of cocaine use with quantitative urinalysis and estimation of new uses. Addiction 92: 717-727.

Simpson D, Joe G, Rowan-Szal G, Greener J (1997). Drug abuse treatment process components that improve retention. J Subst Abuse Treat 14: 565-572.
Simpson DD, Joe GW, Fletcher BW, Hubbard RL, Anglin MD (1999). A national evaluation of treatment outcomes for cocaine dependence. Arch Gen Psychiatry 56: 507-514.

Siqueland L, Crits-Christoph P, Frank A, Daley D, Weiss R, Chittams J et al (1998). Predictors of dropout from psychosocial treatment of cocaine dependence. Drug Alcohol Depend 52: 1-13.

Streeter CC, Hennen J, Ke Y, Jensen JE, Sarid-Segal O, Nassar LE et al (2005). Prefrontal GABA levels in cocaine-dependent subjects increase with pramipexole and venlafaxine treatment. Psychopharmacology 182: 516-526.

Streeter CC, Hennen J, Ke Y, Jensen JE, Sarid-Segal O, Nassar LE et al (2006). Prefrontal GABA levels in cocaine-dependent subjects increase with pramipexole and venlafaxine treatment. (Erratum) Psychopharmacology 185: 404.

Stroop J (1935). Studies of interference in serial verbal reactions. J Exp Psychol 18: 643-662.

Teichner G, Horner MD, Roitzsch JC, Herron J, Thevos A (2002). Substance abuse treatment outcomes for cognitively impaired and intact outpatients. Addict Behav 27: 751-763.

van Gorp WG, Wilkins JN, Hinkins CH, Moore LH, Hull J, Horner MD et al (1999). Delcarative and procedural memory functioning in abstinent cocaine abusers. Arch Gen Psychiatry 56: 85-89.

Volkow ND, Mullani N, Gould KL, Adler S, Krajewski K (1988). Cerebral blood flow in chronic cocaine users: a study with positron emission tomography. Br J Psychiatry 152: 641-648.

Waters AJ, Shiffman S, Sayette MA, Paty JA, Gwaltney CJ, Balabanis $\mathrm{MH}$ (2003). Attentional bias predicts outcome in smoking cessation. Health Psychol 22: 378-387.

Wertz JM, Sayette MA (2001). Effects of smoking opportunity on attentional bias in smokers. Psychol Addict Behav 15: 268-271.

Winhusen TM, Somoza EC, Harrer JM, Mezinskis JP, Montgomery MA, Goldsmith RJ et al (2005). A placebo-controlled screening trial of tiagabine, sertraline and donepezil as cocaine dependence treatments. Addiction 100(Suppl 1): 68-77. 